\title{
PENGENALAN CIRI SUARA SEBAGAI PERINTAH KONTROL ARAH PADA MOBILE ROBOT BERBASIS MIKROKONTROLER STM32F4
}

\author{
Gezaq Abror $^{1}$, Totok Dewantoro ${ }^{2}$, Reffaldi Zuliansyah ${ }^{3}$ \\ Teknologi Listrik, Fakultas Vokasi \\ Universitas 17 Agustus 1945 Surabaya, Indonesia \\ e-mail : 1gezaq@untag-sby.ac.id, 2totok.dewantoro@untag-sby.ac.id, 3reffizuliansya223@gmail.com \\ Diterima: 24 Oktober 2020. Disetujui : 20 Desember 2020. Dipublikasikan : 30 Desember 2020 \\ (C)2020 -TESJ Fakultas Teknik Universitas Maarif Hasyim Latif. Ini adalah artikel dengan \\ akses terbuka di bawah lisensi CC BY 4.0 (https://creativecommons.org/licenses/by/4.0/)
}

\begin{abstract}
ABSTRAK
Teknologi robotika merupakan salah satu teknologi yang sangat dibutuhkan untuk menunjang revolusi industri 4.0. Pengontrolan arah pada mobile robot sangat dibutuhkan agar robot dapat melakukan kegiatan sesuai dengan rancangan yang diinginkan. Dalam pengontrolan arah robot dibutuhkan suatu metode yang praktis dan efisien. Kontrol arah dengan perintah suara berdasarkan pengenalan ciri suara diusulkan pada penelitian ini agar robot dapat bergerak sesuai dengan instruksi pengguna tanpa harus menyentuh robot sehingga metode ini diharapkan mampu mempermudah pengguna dalam memberikan perintah kontrol arah pada mobile robot. Dengan menggunakan metode modified Euclidean Distance yang digunakan untuk mencari jarak terdekat pada ciri input suara berdasarkan referensi suara sehingga dapat dilakukan pengenalan pola suara sebagai perintah kontrol arah pada mobile robot. Metode ini diaplikasikan pada mikrokontroler STM32F4 sebagai kontroler pada mobile robot. Perintah kontrol arah yang digunakan yaitu 'maju', 'mundur', 'kiri', 'kanan' dan 'stop'. Diperoleh rata-rata tingkat keberhasilan $84 \%$ dalam pengenalan perintah kontrol arah pada mobile robot berdasarkan pengenalan ciri suara.
\end{abstract}

Kata kunci: instruksi suara, mobile robot, pengenalan ciri suara, perintah kontrol arah, stm32f4

\section{PENDAHULUAN}

Perkembangan teknologi pada era revolusi industri 4.0 ini sangat pesat sekali, dapat dibuktikan dengan banyaknya riset mengenai teknologi baru yang tepat guna. Seiring dengan perkembangan teknologi ini dibutuhkan kompetensi dari teknologi yang diciptakan. Teknologi yang tepat guna akan memberikan manfaat yang besar bagi kehidupan manusia. Salah satunya yaitu teknologi pengenalan ciri suara.

Manusia membutuhkan teknologi bantu yang dapat menyelesaikan beberapa masalah. Teknologi robotika yang dipadukan dengan teknologi pengenalan ciri suara sangat tepat dalam membantu pekerjaan manusia dikarenakan pekerjaan yang dilakukan dapat terlaksana secara lebih efisien dan manusia tidak perlu mengerjakan tugas tersebut sendiri, cukup hanya dengan perintah suara saja. Dengan bantuan robot yang memanfaatkan pengenalan ciri suara pekerjaan manusia dapat dilakukan secara praktis dikarenakan robot dapat bekerja sesuai konsep yang diberikan berdasarkan pemrosesan perintah suara yang diucapkan.

Teknologi robot merupakan teknologi yang berupa mekanik yang dapat bekerja menggantikan manusia untuk melakukan tugas fisik, baik itu dilakukan dengan kontrol dari manusia atau dengan menggunakan kecerdasan buatan. Robot terdiri dari 2 macam berdasarkan cara bergeraknya yaitu robot beroda/mobile robot dan robot berkaki. Mobile robot merupakan sebuah jenis robot yang dapat berpindah tempat dengan konstruksi robot berupa roda sebagai penggerak sehingga robot dapat berpindah posisi dari satu titik ke titik lain.

Pengenalan ciri suara dapat diaplikasikan pada perintah kontrol arah mobile robot. Dengan memanfaatkan teknologi pengenalan ciri suara, pengguna hanya harus mengucapkan perintah suara berupa perintah kontrol arah untuk menentukan arah gerak mobile robot sehingga mobile robot akan menjalankan perintah dan bergerak sesuai arah yang diinginkan. Dibutuhkan metode pengenalan ciri suara yang baik sehingga mobile robot dapat menterjemahkan perintah kontrol arah dengan tepat.

Permasalahan yang dibahas pada penelitian ini yaitu pada bagian perintah kontrol arah pada mobile robot, dimana dibutuhkan sebuah perintah kontrol arah yang praktis dan efisien sehingga akan memudahkan pengguna dalam pengoperasian mobile robot. Dibuatlah sebuah metode yang dapat memberikan perintah kontrol arah pada mobile robot berupa perintah suara yang mana dalam 
pengaplikasiannya digunakan pengenalan ciri suara. Ketepatan pengolahan masukan berupa sinyal suara menjadi instruksi tertentu untuk memberikan perintah pada mobile robot sangat dibutuhkan. Digunakan mikrokontroler STM32F4 pada sistem kontrol pengolahan ciri sinyal suara dengan input dari mikrofon kondensor yang telah dikuatkan dan dilakukan filter sehingga diharapkan akan mampu mengendalikan kontrol arah mobile robot.

Tujuan dari penelitian ini yaitu pembuatan sistem mobile robot yang mampu mengenali perintah kontrol arah berupa sinyal suara secara tepat sehingga akan memudahkan pengguna dalam pengoperasian mobile robot.

Penelitian terkait yang digunakan sebagai rujukan dalam penelitian ini yaitu beberapa penelitian mengenai bidang robotika dan perintah suara yang sudah ada sebelumnya. Yasir Ali Memon (Memon, Motan, Akbar, Hameed, \& Hasan, 2016) meneliti tentang penggunaan google speech processing libraries pada platform Android yang dikomunikasikan secara bluetooth dengan vehicle robot sebagai pengendalinya. Penelitian ini menghasilkan pengenalan yang efisien dan pengiriman data secara smooth.

N.U Alka (Alka, Salihu, Haruna, \& Dalyop, 2017) meneliti tentang penggunaan aplikasi pengolah suara pada android sebagai pengontrol robot arm vehicle. Aplikasi android tersebut menterjemahkan perintah suara dan data penterjemahan tersebut dikirimkan dengan komunikasi bluetooth ke robot arm vehicleI yang berbasis Arduino. Pembacaan perintah suara pada aplikasi android berjalan dengan baik dan mampu berkomunikasi dengan robot pada jarak 12 meter.

Eko Sulistyo (Sulistyo, 2019) meneliti tentang penggunaan instruksi suara yang direkam pada aplikasi Android dan digunakan sebagai kontrol mobile robot yang berbasis mikrokontroler Arduino Mega2560. Pengiriman data dari Android ke mobile robot menggunakan bluetooth. Hasil yang diperoleh yaitu 1,55\% untuk error pergerakan rata-rata dan waktu respon 4-7 detik.

Humayun Rashid (Rashid et al., 2017) meneliti tentang penggunaan aplikasi android yang mengirimkan data text menggunakan bluetooth kepada robot yang berbasis Arduino Uno. Robot ini juga dilengkapi dengan kemampuan berbicara yang digunakan untuk berinteraksi dengan manusia berupa data suara yang sebelumnya pernah direkam. Penelitian ini menghasilkan robot yang dapat bergerak berdasarkan perintah suara yang dikirimkan oleh smartphone Android secara bluetooth.

Koksal Gundogdu (Gundogdu, Bayrakdar, \& Yucedag, 2018) meneliti tentang sistem pengendalian berbasis suara yang diterapkan pada arm robot dengan pembuatan model matematika dari suara yang digunakan oleh Qidwai. Penelitian ini menyatakan bahwa teknik pengenalan suara yang digunakan lebih efisien $11 \%$ dari teknik pengenalan suara yang lain yang digunakan dalam literatur penelitiannya.

\section{METODE PENELITIAN}

Pada penelitaian ini metode pelaksanaan yang digunakan yaitu meliputi perancangan sistem pengolahan input suara pada mobile robot, perancangan prinsip kerja sistem, pengambilan database suara dan proses pengenalan suara berdasarkan ciri suara.

\section{Sistem Pengolahan Input Suara pada Mobile Robot}

Tahapan ini merupakan tahapan untuk melakukan perancangan terhadap sistem pengolah input suara yang digunakan pada mobile robot. Sistem ini direpresentasikan oleh Gambar 1.

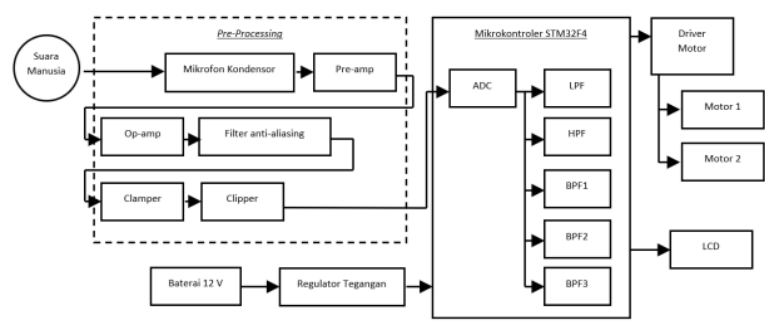

Gambar 1. Blok diagram sistem pengolahan input suara pada sistem mobile robot

Parameter yang digunakan sebagai masukan pada sistem ini yaitu suara manusia. Tahap awal sinyal suara ini diolah pada bagian Pre-Processing. Suara manusia diterima oleh mikrofon kondensor, dikarenakan sinyal suara yang diterima oleh mikrofon kondensor ini keluarannya sangat kecil maka selanjutnya dilakukan proses penguatan yaitu dengan rangkaian pre-amplifier (pre-amp) dan operational amplifier (op-amp). Sinyal suara dikuatkan 15 kali oleh rangkaian pre-amp dan dikuatkan lagi 10 kali dengan rangkaian op-amp. Lalu selanjutnya sinyal suara akan masuk pada rangkaian filter anti-aliasing yang berguna untuk menghilangkan frekuensi yang berada diluar jangkauan ADC (Analog to Digital Converter) pada mikrokontroler STM32F4. Filter anti-aliasing ini menggunakan Low Pass Filter 4Khz (yang mana nilai ini diambil dari setengah frekuensi sampling yaitu $8 \mathrm{KHz}$ ). Selanjutnya sinyal suara masuk ke rangkaian Clamper untuk dilakukan penggeseran sinyal sehingga bisa digunakan sebagai data pada mikrokontroler STM32F4 dan dilanjutkan ke rangkaian Clipper untuk dilakukan pembatasan data sinyal suara yang masuk kedalam mikrokontroler STM32F4.

Setelah melalui tahap Pre-Processing maka sinyal suara digunakan sebagai data yang akan 
diolah pada sistem mikrokontroler STM32F4. Data yang masuk beruapa data analog akan diterima oleh ADC dan diubah menjadi data digital. Lalu dilakukan proses filtering dengan menggunakan filter digital dengan 5 parameter filter yaitu Low Pass Filter (LPF), High Pass Filter (HPF) dan 3 buah Band Pass Filter (BPF). Selanjutnya data tersebut akan diolah dan dijadikan sebagai keputusan untuk menggerakkan motor (bagian roda robot) untuk bergerak sesuai perintah kontrol arah.

\section{Prinsip Kerja Sistem}

Prinsip kerja dari sistem mobile robot yang digunakan terdiri dari 2 tahapan yaitu tahap pengambilan/perekaman database suara dan tahap pengujian pengenalan suara. Ketika sistem dijalankan maka akan ada 2 menu pilihan berdasarkan 2 tahapan yang sudah dirancang. Ketika pengguna menginginkan menu perekaman/pengambilan database suara, maka suara pengguna akan disimpan pada internal memory mikrokontroler STM32F4 sebagai referensi data untuk perintah kontrol arah yaitu 'maju', 'mundur', 'kiri', 'kanan' dan 'stop'. Pada menu pengujian pengenalan suara, pengguna akan menyebutkan kata perintah kontrol arah dan selanjutnya sistem akan mencocokkan dengan database suara yang sebelumnya disimpan pada internal memory mikrokontroler STM32F4, lalu diambil keputusan sebagai perintah arah pergerakan mobile robot dengan menggerakkan 2 buah motor yang sudah dipasang sebagai penggerak/aktuator. sistem mobile robot ini juga dilengkapi dengan LCD (Liquid Crystal Display) sebagai penampil data.

\section{Pengambilan Database Suara}

Pengambilan/perekaman database suara harus dilakukan agar diperoleh data yang nantinya akan dijadikan sebagai referensi data suara ketika dibandingkan dengan data suara masukan pada saat proses pengujian pengenalan suara. Proses ini sangat diperlukan karena pada saat proses pengenalan ciri suara membutuhkan dua buah data yaitu data masukan dan data referensi yang natinya akan dibandingkan sehingga menghasilkan keputusan yang tepat. Data referensi yang disimpan pada database ini meliputi data untuk perintah kontrol arah yaitu 'maju', 'mundur', 'kiri', 'kanan' dan 'stop'.

Dapat dilihat pada Gambar 2, suara yang masuk akan diolah terlebih dahulu oleh bagian preprocessing lalu akan masuk ke mikrokontroler STM32F4 dan dijadikan sinyal digital oleh ADC, lalu data sinyal digital tersebut akan melaui proses filter yang dilakukan oleh filter digital. Untuk filter digital yang digunakan yaitu filter FIR yang terdiri dari 5 buah filter. Penggunaan 5 buah filter ini dimaksudkan agar diperoleh data ciri masing- masing suara sebagai perintah kontrol arah secara akurat, karena semakin banyak ciri yang digunakan maka data tersebut akan semakin akurat. Hasil keluaran filter digital ini berupa nilai data digital untuk masing-masing filter yaitu LPF, HPF, BPF1, BPF2 dan BPF3. Dalam penentuan range filter, sebelumnya telah dilakukan pengidentifikasian frekuensi dominan dari masing-masing suara sebagai perintah kontrol arah. Nilai data digital hasil masing-masing filter ini akan disimpan sebagai data referensi pada internal memory mikrokontroler STM32F4.

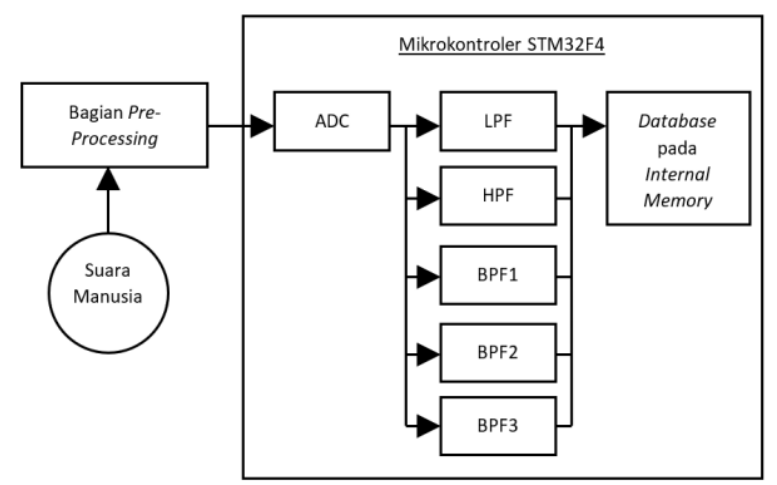

Gambar 2. Proses pengambilan/perekaman database suara pada sistem mobile robot

\section{Proses Pengenalan Suara berdasarkan Ciri Suara}

Proses pengenalan suara berdasarkan ciri suara yang direpresentasikan pada Gambar 3 merupakan proses inti untuk pengambilan keputusan perintah kontrol arah pada mobile robot.

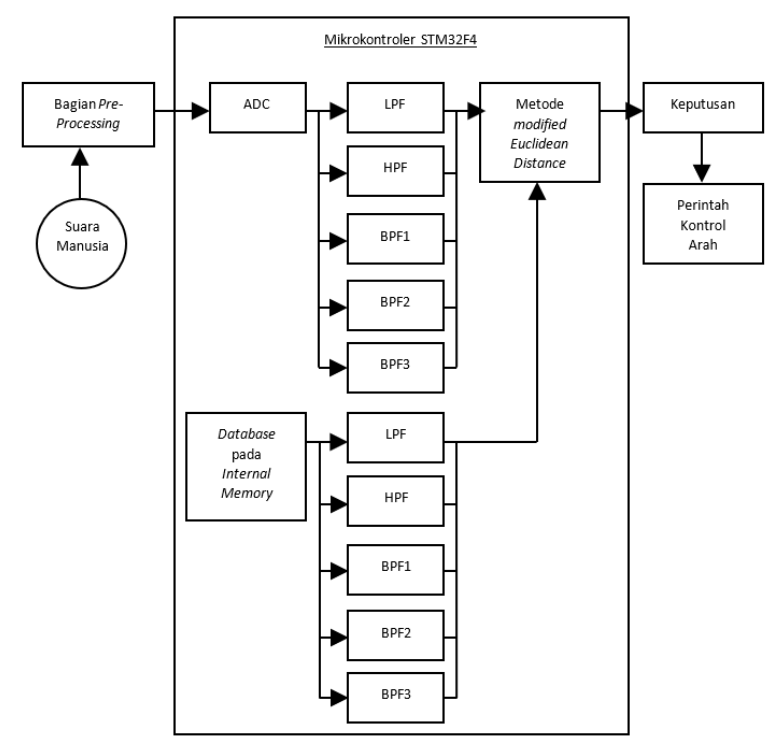

Gambar 3. Proses pengenalan suara berdasarkan ciri suara pada sistem mobile robot

Proses ini dilakukan saat mobile robot dalam mode pengujian pengenalan suara, lalu dilakukan pengambilan data masukan berupa suara manusia yang selanjutnya diolah oleh bagian pre-processing 
dan filter digital. Data masukan suara tersebut selanjutnya akan dibandingkan dengan data referensi suara yang sebelumnya sudah disimpan pada internal memory mikrokontroler STM32F4 dengan mencari data yang paling mendekati dengan data referensi suara ketika nilai LPF, HPF, BPF1, BPF2 dan BPF3 dibandingkan. Proses pembandingan data ini menggunakan metode modified Euclidean Distance seperti pada persamaan 1 dan 2 yang merupakan modifikasi dari metode Euclidean Distance. Euclidean Distance merupakan metode yang diaplikasikan sebagai pengukuran jarak antara 2 titik yang berbeda.

$$
\begin{aligned}
& d_{-} \text {suara }_{i j}=\sqrt{\sum_{k=1}^{5}\left(\text { input }_{i k}-\text { referensi }_{j k}\right)^{2}} \\
& d_{-} \operatorname{suara}_{i j}<d_{\min } \Rightarrow d_{\text {min }}=d_{-} s u a r a_{i j}
\end{aligned}
$$

Metode modified Euclidean Distance ini digunakan karena metode ini tidak membutuhkan algoritma yang rumit sehingga waktu pemrosesan/eksekusi datanya relatif singkat dan metode ini juga merupakan metode yang paling aplikatif untuk diterapkan pada sebuah sistem mikrokontroler. Berdasarkan hasil nilai data perbandingan suara yang paling mendekati dengan data yang ada pada database tersebut maka akan dipergunakan sebagai pengambilan keputusan perintah kontrol arah pada mobile robot.

\section{HASIL DAN PEMBAHASAN}

\section{Frekuensi Dominan dari Suara Perintah Kontrol Arah}

Frekuensi dominan merupakan nilai frekuensi yang merupakan ciri suara yang dipergunakan sebagai acuan dalam perintah kontrol arah mobile robot. Suara yang digunakan sebagai masukan (data uji) adalah suara penulis yang berjenis kelamin laki-laki. Pengidentifikasian frekuensi dominan ini dugunakan sebagai proses pembuatan filter atau dalam kata lain penentuan besarnya nilai range filter yang digunakan untuk filter digital yang dibuat yaitu LPF, HPF, BPF1, BPF2 dan BPF3.

Tahap pertama yang dilakukan dalam pengidentifikasian frekuensi dominan adalah observasi suara dengan merekam suara. Agar dapat diketahui frekuensi dominan dari sinyal suara perintah kontrol arah, maka digunakan metode FFT (Fast Fourier Transform) yang disimulasikan menggunakan software Matlab. Perhitungan FFT dapat ditunjukkan dengan persamaan 3 .

$$
s(f)=\int_{-\infty}^{\infty} s(t) e^{-j 2 \pi f t} d t
$$

Dimana nilai s(f) merupakan sinyal pada domain frekuensi, $s(\mathrm{t})$ merupakan sinyal pada domain waktu, $e^{-j 2 \pi f t}$ merupakan konstanta sinyal. Penggunaan software Matlab ini dimaksudkan agar terjadi proses mengubah sinyal suara menjadi image sehingga dapat ditentukan frekuensi minimal dan frekuensi maksimal masingmasing suara.
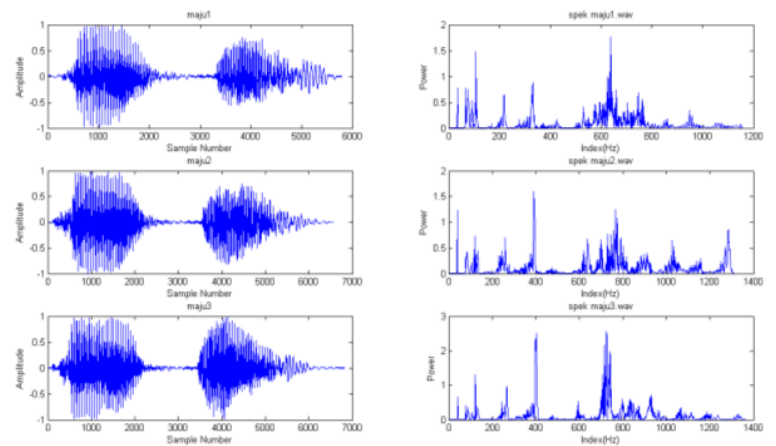

Gambar 4. Hasil observasi suara untuk perintah 'maju'

Gambar 4 menunjukkan proses observasi suara untuk perintah 'maju' dengan pengubahan sinyal suara perintah 'maju' yang telah direkam melalui software perekam menjadi grafik FFT dengan 3 buah data uji sinyal suara perintah 'maju'. Diperoleh nilai frekuensi dominan untuk perintah 'maju' yaitu pada indeks suara $100 \mathrm{~Hz}, 250 \mathrm{~Hz}, 400$ $\mathrm{Hz}$ dan $700 \mathrm{~Hz}$.
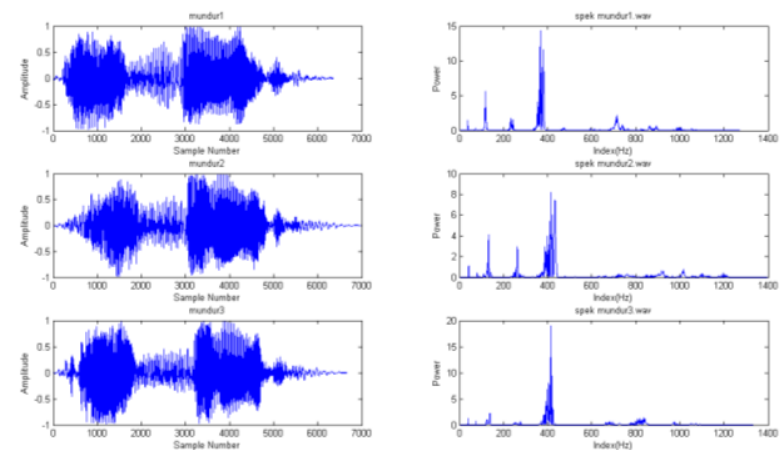

Gambar 5. Hasil observasi suara untuk perintah 'mundur'

Gambar 5 menunjukkan proses observasi suara untuk perintah 'mundur' dengan pengubahan sinyal suara perintah 'mundur' yang telah direkam melalui software perekam menjadi grafik FFT dengan 3 buah data uji sinyal suara perintah 'mundur'. Diperoleh nilai frekuensi dominan untuk perintah 'mundur' yaitu pada indeks suara $100 \mathrm{~Hz}$ dan $400 \mathrm{~Hz}$.

Gambar 6 menunjukkan proses observasi suara untuk perintah 'kiri' dengan pengubahan sinyal suara perintah 'kiri' yang telah direkam melalui software perekam menjadi grafik FFT 
dengan 3 buah data uji sinyal suara perintah 'kiri'. Diperoleh nilai frekuensi dominan untuk perintah 'kiri' yaitu pada indeks suara $50 \mathrm{~Hz}$ dan $300 \mathrm{~Hz}$.
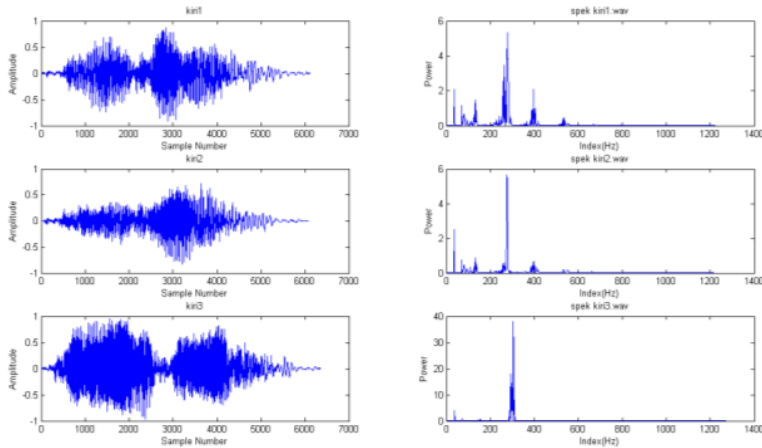

Gambar 6. Hasil observasi suara untuk perintah 'kiri'
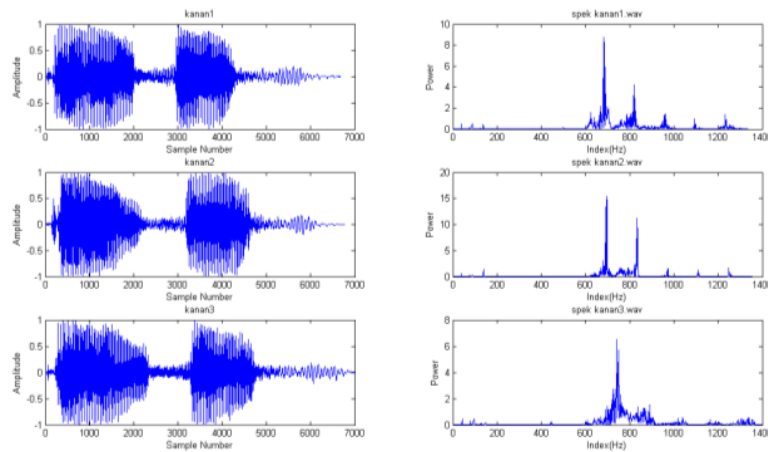

Gambar 7. Hasil observasi suara untuk perintah 'kanan'

Gambar 7 menunjukkan proses observasi suara untuk perintah 'kanan' dengan pengubahan sinyal suara perintah 'kanan' yang telah direkam melalui software perekam menjadi grafik FFT dengan 3 buah data uji sinyal suara perintah 'kanan'. Diperoleh nilai frekuensi dominan untuk perintah 'kanan' yaitu pada indeks suara $700 \mathrm{~Hz}$ dan $850 \mathrm{~Hz}$.
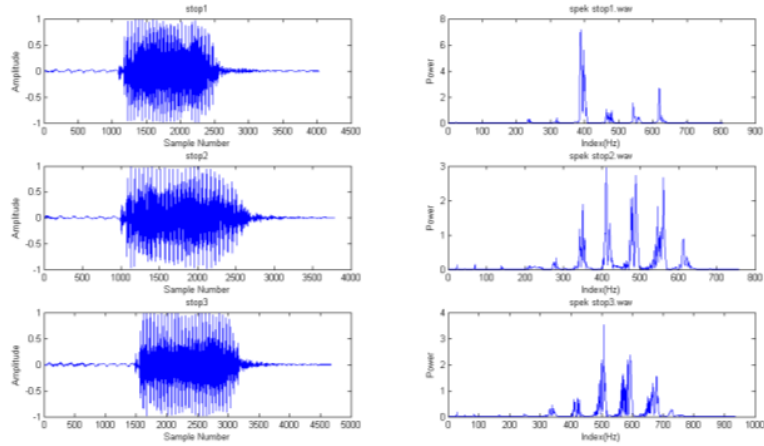

Gambar 8. Hasil observasi suara untuk perintah 'stop'

Gambar 8 menunjukkan proses observasi suara untuk perintah 'stop' dengan pengubahan sinyal suara perintah 'stop' yang telah direkam melalui software perekam menjadi grafik FFT dengan 3 buah data uji sinyal suara perintah 'stop'. Diperoleh nilai frekuensi dominan untuk perintah 'stop' yaitu pada indeks suara $350 \mathrm{~Hz}, 420 \mathrm{~Hz}, 500$ $\mathrm{Hz}$ dan $600 \mathrm{~Hz}$.
Tabel 1. Indeks frekuensi dari masing-masing data uji perintah suara kontrol arah

\begin{tabular}{ccc}
\hline $\begin{array}{c}\text { Data uji } \\
\text { perintah suara }\end{array}$ & $\begin{array}{c}\text { Indeks frekuensi } \\
\text { minimal (Hz) }\end{array}$ & $\begin{array}{c}\text { Indeks frekuensi } \\
\text { maksimal (Hz) }\end{array}$ \\
\hline 'maju' 1 & 50 & 1200 \\
'maju' 2 & 50 & 1250 \\
'maju' 3 & 50 & 1250 \\
'mundur' 1 & 50 & 1050 \\
'mundur' 2 & 50 & 1200 \\
'mundur' 3 & 50 & 1050 \\
'kiri' 1 & 50 & 590 \\
'kiri' 2 & 50 & 590 \\
'kiri' 3 & 50 & 550 \\
'kanan' 1 & 50 & 1300 \\
'kanan' 2 & 50 & 1300 \\
'kanan' 3 & 50 & 1350 \\
'stop' 1 & 50 & 710 \\
'stop' 2 & 50 & 710 \\
'stop' 3 & 50 & 720 \\
\hline Rata-rata & 50 & 751,33 \\
\hline
\end{tabular}

Pada Tabel 1 ditunjukkan besarnya nilai indeks frekuensi untuk masing-masing data uji perintah suara sebagai kontrol arah mobile robot. Dapat diketahui bahwa indeks frekuensi minimal untuk semua data uji perintah suara yaitu $50 \mathrm{~Hz}$ dengan nilai rata-rata keseluruhan indeks frekuensi minimal yaitu $50 \mathrm{~Hz}$. Sedangkan untuk indeks frekuensi maksimal tertinggi yaitu pada perintah suara 'kanan' data uji ke-3 dengan nilai yaitu $1350 \mathrm{~Hz}$ dan nilai rata-rata keseluruhan indeks frekuensi maksimal yaitu 751,33 Hz. Sehingga dari data hasil indeks frekuensi minimal dan indeks frekuensi maksimal dengan memperhatikan frekuensi dominan untuk masingmasing data uji perintah suara maka dibuatlah range filter digital yaitu $\mathrm{LPF}=400 \mathrm{~Hz}, \mathrm{HPF}=600$ $\mathrm{Hz}, \mathrm{BPF} 1=100 \mathrm{~Hz}-300 \mathrm{~Hz}, \mathrm{BPF} 2=400-600 \mathrm{~Hz}$ dan BPF3 $=700 \mathrm{~Hz}-900 \mathrm{~Hz}$.

\section{Nilai Data Digital Database Suara Perintah Kontrol Arah pada Sistem Mobile Robot}

Tabel 2. Data referensi suara perintah kontrol arah

\begin{tabular}{cccccc}
\hline \multirow{2}{*}{ Perintah kontrol arah } & \multicolumn{5}{c}{ Data digital (12 bit) } \\
\cline { 2 - 6 } & LPF & HPF & BPF1 & BPF2 & BPF3 \\
\hline 'maju' & 1549 & 1375 & 1215 & 965 & 1154 \\
'mundur' & 2526 & 77 & 1433 & 1532 & 54 \\
'kiri' & 2967 & 23 & 1790 & 47 & 35 \\
'kanan' & 44 & 2697 & 52 & 81 & 2863 \\
'stop' & 1286 & 1183 & 1034 & 2105 & 121 \\
\hline
\end{tabular}

Dalam pengambilan data referensi suara perintah kontrol arah yang disimpan sebagai database dalam internal memory mikrokontroler STM32F4 pada sistem mobile robot maka dihasilkan sebuah nilai data digital (12 bit) yang merupakan ciri suara berdasarkan dari hasil keluaran filter digital yang telah dibuat. Filter digital yang digunakan pada sistem mobile robot yaitu LPF $=400 \mathrm{~Hz}$ orde-15, HPF $=600 \mathrm{~Hz}$ orde-15, 
BPF1 $=100 \mathrm{~Hz}-300 \mathrm{~Hz}$ orde-15, BPF2 $=400-600$ Hz orde-15 dan BPF3 $=700 \mathrm{~Hz}-900 \mathrm{~Hz}$ orde- 15 .

Tabel 2 menunjukkan nilai data digital database suara perintah kontrol arah pada sistem mobile robot yang digunakan sebagai data referensi. Pada perintah 'maju' didapatkan hasil dominan pada hasil nilai LPF (1549), HPF (1375), BPF1 (1215), BPF2 (965) dan BPF3 (1154). Pada perintah 'mundur' didapatkan hasil dominan pada hasil nilai LPF (2526), BPF1 (1433) dan BPF2 (1532). Pada perintah 'kiri' didapatkan hasil dominan pada hasil nilai LPF (2967) dan BPF1 (1790). Pada perintah 'kanan' didapatkan hasil dominan pada hasil nilai HPF (2697) dan BPF3 (2863). Sedangkan, pada perintah 'stop' didapatkan hasil dominan pada hasil nilai LPF (1286), HPF (1183), BPF1 (1034) dan BPF2 (2105).

\section{Pengujian Pengenalan Suara berdasarkan Ciri Suara pada Sistem Mobile Robot}

Pengujian pengenalan suara merupakan tahapan proses pengambilan keputusan berdasarkan perintah kontrol arah yang sudah diberikan yaitu 'maju', 'mundur', 'kiri', 'kanan' dan 'stop' sehingga mobile robot dapat bergerak sesuai dengan arahan. Metode modified Euclidean Distance akan membandingkan data suara baru yang masuk dengan data referensi yang merupakan database suara perintah kontrol arah (ciri suara).

Tabel 3. Pengenalan suara berdasarkan ciri suara pada sistem mobile robot

\begin{tabular}{cccc}
\hline \multirow{3}{*}{$\begin{array}{c}\text { Perintah kontrol } \\
\text { arah }\end{array}$} & $\begin{array}{c}\text { Pengenalan suara } \\
\text { 20 kali percobaan } \\
\text { setiap suara) }\end{array}$ & $\begin{array}{c}\text { Persentase } \\
\text { keberhasilan } \\
(\%)\end{array}$ \\
\cline { 2 - 3 } & Benar & Salah & \\
\hline 'maju' & 17 & 3 & 85 \\
'mundur' & 16 & 4 & 80 \\
'kiri' & 15 & 5 & 75 \\
'kanan' & 17 & 3 & 85 \\
'stop' & 19 & 1 & 95 \\
\hline Rata-rata & 16,8 & 3,2 & 84 \\
\hline
\end{tabular}

Tabel 3 menunjukkan hasil dari pengujian pengenalan suara berdasarkan ciri suara pada sistem mobile robot. Dilakukan sebanyak 20 kali percobaan untuk setiap perintah kontrol arah. Pada perintah 'maju' didapatkan hasil yaitu benar sebanyak 17 kali sehingga tingkat keberhasilannya $85 \%$. Pada perintah 'mundur' didapatkan hasil yaitu benar sebanyak 16 kali sehingga tingkat keberhasilannya $80 \%$. Pada perintah 'kiri' didapatkan hasil yaitu benar sebanyak 15 kali sehingga tingkat keberhasilannya $75 \%$. Pada perintah 'kanan' didapatkan hasil yaitu benar sebanyak 17 kali sehingga tingkat keberhasilannya $85 \%$. Sedangkan, pada perintah 'stop' didapatkan hasil yaitu benar sebanyak 19 kali sehingga tingkat keberhasilannya $95 \%$. Untuk tingkat keberhasilan rata-rata pengenalan suara berdasarkan ciri suara pada sistem mobile robot yaitu sebesar $84 \%$.

\section{PENUTUP}

Pada penelitian ini pengenalan ciri suara diusulkan sebagai perintah kontrol arah pada mobile robot. Sistem mobile robot dilengkapi dengan mikrokontroler STM32F4 sebagai perangkat pengolah data masukan berupa sinyal suara untuk perintah kontrol arah yaitu 'maju', 'mundur', 'kiri', 'kanan' dan 'stop'. Diperoleh indeks frekuensi minimal rata-rata untuk semua perintah suara yaitu $50 \mathrm{~Hz}$ dan indeks frekuensi maksimal rata-rata untuk semua perintah suara yaitu 751,33 Hz. Dengan menggunakan metode modified Euclidean Distance dilakukan perbandingan data masukan suara dengan data referensi suara dan hasilnya dipergunakan sebagai pengambilan keputusan arah gerak mobile robot berdasarkan perintah kontrol arah. Tingkat keberhasilan ratarata pengenalan suara berdasarkan ciri suara pada sistem mobile robot yaitu sebesar $84 \%$. Untuk memperbaiki kemampuan identifikasi pengenalan suara dapat dilakukan pengembangan metode yang dipergunakan sebagai contoh penggunaan metote DTW (Dynamic Time Wrapping) dan penggunaan parameter identifikasi suara yang lebih banyak.

\section{DAFTAR PUSTAKA}

Alka, N. U., Salihu, A. A., Haruna, Y. S., \& Dalyop, I. A. (2017). A voice controlled pick and place robotic arm vehicle using android application. American Journal of Engineering Research, 6(7), 207-215.

Gumilar, Z. A., \& Lubis, D. (2017). Rancang Bangun Sistem Autonomous pada Robot Beroda dengan Global Positioning System (GPS). Seminar Nasional Kelautan XII: Inovasi Hasil Riset Dan Teknologi Dalam Rangka Penguatan Kemandirian Pengelolaan Sumber Daya Laut Dan Pesisir. Surabaya: Fakultas Teknik dan Ilmu Kelautan Universitas Hang Tuah.

Gundogdu, K., Bayrakdar, S., \& Yucedag, I. (2018). Developing and modeling of voice control system for prosthetic robot arm in medical systems. Journal of King Saud University Computer and Information Sciences, 30(2), 198-205.

Lumenta, A. S. M. (2012). Pemanfaatan Komputer Tablet Android Sebagai Pengendali Robot Beroda Empat. Jurnal Teknik Elektro Dan Komputer, 1(4), 1-7.

Memon, Y. A., Motan, I., Akbar, M. A., Hameed, S., \& 
Hasan, M. U. (2016). Speech Recognition System for a Voice Controlled Robot with Real Time Obstacle Detection and Avoidance. International Journal of Electrical, Electronics And Data Communication, 4(9), 33-37.

Rashid, H., Ahmed, I. U., Osman, S. Bin, Newaz, B., Rasheduzzaman, M., \& Reza, S. M. T. (2017). Design and implementation of a voice controlled robot with human interaction ability. International Conference on Computer, Communication, Chemical, Materials and Electronic Engineering, 65, 148-151.

Riyani, A., Nurrochman, A., Sanjaya, E., Rizqiyah, P., \& Junaidi, A. (2019). Mengidentifikasi Sinyal Suara Manusia Menggunakan Metode Fast Fourier Transform (FFT) Berbasis Matlab. Journal of Informatics, Information System, Software Engineering and Applications, 1(2), 42-50.

Rizaldi, R., Kurniawati, A., \& Angkoso, C. V. (2018). Implementasi metode Euclidean distance untuk rekomendasi ukuran pakaian pada aplikasi ruang ganti virtual. Jurnal Teknologi Informasi Dan Ilmu Komputer, 5(2), 129138.
Sulistyo, E. (2019). Mobile Robot Dengan Pengontrolan Perintah Suara Berbasis Android. Manutech: Jurnal Teknologi Manufaktur, 9(02), 9-14. https://doi.org/10.33504/manutech.v9i02. 40 
G Abror, dkk / Teknika : Engineering and Sains Journal, Vol. 4, No.2, Desember 2020, 35-42

halaman ini sengaja dikosongkan 